\title{
Routine Check-Ups and Other Factors Affecting Discussions With a Health Care Provider About Subjective Memory Complaints, Behavioral Risk Factor Surveillance System, 21 States, 2011
}

\author{
Mary Adams, MS, MPH
}

Suggested citation for this article: Adams M. Routine Check-Ups and Other Factors Affecting Discussions With a Health Care Provider About Subjective Memory Complaints, Behavioral Risk Factor Surveillance System, 21 States, 2011. Prev Chronic Dis 2016;13:150471. DOI: http://dx.doi.org/10.5888/pcd13.150471.

\section{PEER REVIEWED}

\section{Abstract}

\section{Introduction}

Most adults reporting subjective memory complaints (SMCs) do not discuss them with a health care provider and miss an opportunity to learn about treatment options or receive a diagnosis. The objective of this study was to describe correlates of discussing memory problems with a health care professional among adults reporting SMCs.

\section{Methods}

Data were from 10,276 respondents aged 45 years or older in 21 states reporting SMCs on the 2011 Behavioral Risk Factor Surveillance System (BRFSS). Odds ratios (ORs) adjusted for demographic and health-related measures were computed for discussing SMCs with a health care professional.

\section{Results}

Among all respondents aged 45 or older reporting SMCs, 22.9\% reported discussing them with a health care professional; among those reporting a recent routine check-up, this rate was $25.2 \%$. The largest adjusted OR for discussing SMCs with a health care professional was for respondents reporting that SMCs always (vs never) caused them to give up household chores (OR, 3.02) or always (vs never) interfered with work (OR, 2.98). Increasing age re- duced the likelihood of discussing SMCs. Among respondents who discussed SMCs, $41.8 \%$ received treatment.

\section{Conclusion}

Routine check-ups may be a missed opportunity for discussions of SMCs that might lead to diagnosis or treatment. The Affordable Care Act requires a cognitive assessment for Medicare recipients during their annual wellness visit, but these results suggest that adults younger than 65 might also benefit from such an assessment.

\section{Introduction}

Although the US Preventive Services Task Force (1) does not recommend routine screening for dementia, which is often first manifested in memory problems, early diagnosis is important for numerous reasons. These include ruling out treatable causes of memory problems not related to dementia, providing a better chance for treatment to be effective, offering enrollment in clinical trials, and discussing community services (2-4). Another important consideration is identifying memory problems at a stage when the individual is still able to participate in decision making about his or her own future. The Affordable Care Act requires that Medicare recipients receive a cognitive assessment during their covered annual wellness visit (5), and recommendations for tools to use during this assessment are available (6).

The Healthy Aging Program at the Centers for Disease Control and Prevention (CDC) developed an optional module for use on the Behavioral Risk Factor Surveillance System (BRFSS) that addresses cognitive health and decline (7-10). The first question addresses confusion or memory loss that is happening more often or is getting worse during the past 12 months, defined hereinafter as subjective memory complaints (SMCs). Follow-up BRFSS ques- 
tions address the need for help, functional difficulties, whether the respondent discussed the increased confusion or memory loss with a health care professional, and if so, whether or not treatment was received. Discussions with a health care professional about memory problems could serve some of the same purposes as assessment by providing an opportunity to learn about services and treatment. This study was conducted to determine how many adults reporting SMCs discussed their memory problems with a health care professional, the factors associated with that action, and the proportion who received treatment. Of special interest were respondents reporting a routine check-up within the previous year.

\section{Methods}

Data were from publicly available (11) BRFSS data collected in 2011 by 21 states (Arkansas, California, Florida, Hawaii, Iowa, Illinois, Louisiana, Maryland, Michigan, North Carolina, Nebraska, New Hampshire, New York, Oklahoma, South Carolina, Tennessee, Texas, Utah, Washington, Wisconsin, West Virginia) that included the cognitive impairment module (7). The BRFSS collects data from noninstitutionalized adults aged 18 or older through monthly random-digit-dial telephone surveys (12) and uses a complex sample design to randomly select respondents with either landline or cellular telephones. Data are weighted to account for the probability of selection of respondents and are further adjusted to be representative of the total adult population of each state by age, race/ethnicity, sex, marital status, education, home ownership, and type of telephone service. Data for this study were limited to the 121,304 landline surveys and excluded cellular telephone surveys, which were available for only 7 of the 21 states. Because 9 states used the cognitive impairment module on split surveys, data from different survey versions were combined and the weighting variables were renamed to be the same, as described by CDC (13). The median survey response rate for landline surveys in the 21 states in 2011 was $53.4 \%$, ranging from $37.4 \%$ in California to $66.0 \%$ in Nebraska (14).

Respondents answering yes to the question "During the past 12 months, have you experienced confusion or memory loss that is happening more often or is getting worse?" were defined as reporting SMCs. Based on preliminary results of SMCs by age group for ages 18 to $24(5.3 \%), 25$ to $34(6.9 \%), 35$ to $44(7.5 \%)$, 45 to $54(12.2 \%), 55$ to $64(12.2 \%)$, and 65 or older $(13.0 \%)$, data were restricted to the 95,147 respondents aged 45 or older. This group included $86.7 \%$ of all respondents reporting SMCs $(10,583$ of 12,205); the same age cutoff was used for these data in another study (10). A follow-up question for those reporting SMCs asked about the areas in which they need the most assistance as a result of their confusion or memory loss. Possible answers were 1) safety, 2) transportation, 3) household activities, 4) personal care 5) need assistance but not in those areas, or 6) no assistance needed in any area. Responses were dichotomized into need help or not. Respondents with functional difficulties were determined from responses to 2 questions and included those who responded that, during the previous 12 months, they always, usually, or sometimes (as opposed to rarely or never) gave up household activities or chores they used to do because of SMCs; or SMCs always, usually, or sometimes (as opposed to rarely or never) interfered with their ability to work, volunteer, or engage in social activities; or both. These measures were also each used separately in logistic regression as 5-level measures, with never as the referent. Additional questions asked whether their confusion or memory loss was discussed with a health care professional (yes/ no), whether they received treatment such as therapy or medications for confusion or memory loss (yes/no), and whether a health care professional ever said they had Alzheimer's disease or some other dementia (answers of yes to Alzheimer's disease or other dementia were combined vs no diagnosis). Respondents who had not discussed their SMCs with a health care provider were not asked about treatment or diagnosis, so those records were coded as no.

Other measures included age (45-54, 55-64, 65-74, 75-84, and $\geq 85 \mathrm{y}$ ), sex, education ( $<$ high school, high school graduate, some college, and college graduate), annual income $(<\$ 15,000$, $\$ 15,000-\$ 24,999, \$ 25,000-\$ 49,999$, \$50,000-\$74,999, and $\geq \$ 75,000$ ), race/ethnicity (non-Hispanic white, non-Hispanic black or African American, Hispanic of any race, and other), disability (limited in any way in any activities or use special equipment [yes/ no]), ever diagnosed with depression (yes/no), health status (excellent, very good, or good vs fair or poor), reporting any of 6 chronic diseases (arthritis, asthma, cardiovascular disease, cancer other than skin, chronic obstructive pulmonary disease, or diabetes [yes/ no]), weight status (body mass index <18.5, 18.5-24.9, 25.0-29.9, $30.0-34.9$, and $\geq 35.0$ ), reporting a cost barrier to health care (Was there a time in the past 12 months when you needed to see a doctor but could not because of cost? [yes/no]), having one or more personal doctors (yes/no), health insurance (yes/no), reporting a routine check-up within the previous year (yes/no) (hereinafter referred to as a recent check-up), current smoking (yes/no), and state of residence.

Stata version 14.0 (StataCorp LP) was used for all analysis to account for the complex sample design of the BRFSS; analysis used the landline weight or the corresponding weight for states that had multiple survey versions. Pearson $\chi^{2}$ tests of association $(\alpha=.05)$ from cross-tabulations of talking with a health care professional about their SMCs and demographic and health-related measures were used to select variables to include in the multivariate logistic regression model. Adjusted odds ratios (ORs) and 95\% confid-

The opinions expressed by authors contributing to this journal do not necessarily reflect the opinions of the U.S. Department of Health and Human Services, the Public Health Service, the Centers for Disease Control and Prevention, or the authors' affiliated institutions. 
ence intervals (CIs) are reported for the final logistic regression model after removal of variables that had $P$ values $>.05$. For all measures, refusal to answer or responses of "don't know" were excluded. Excluding respondents with missing values for having a discussion with a health care professional reduced the sample size from 10,583 to 10,276 .

\section{Results}

One in 8 respondents age 45 or older $(12.5 \% ; 95 \% \mathrm{CI}$, $12.0 \%-13.0 \%$ ) reported SMCs, with minor (but significant) variation $(11.9 \%-15.6 \%)$ across the 5 age groups. Compared with respondents aged 45 or older not reporting SMCs, those reporting SMCs were more likely to live in California $(22.4 \%$ vs $17.1 \%)$; be Hispanic (14.4\% vs $11.2 \%$ ), aged 75 or older (17.6\% vs $15.0 \%)$, and currently smoke ( $24.5 \%$ vs $15.2 \%)$; they were less likely to be white $(68.1 \%$ vs $72.5 \%)$. They also reported less education and lower income, whereas sex distribution was similar for both groups.

Among the 10,276 respondents aged 45 or older reporting SMCs, $22.9 \%$ (95\% CI, $21.1 \%-24.9 \%$ ) reported discussing their memory problems with a health care professional. Significant differences in the percentages of adults who talked to a health care professional about their SMCs are shown in Table 1. Of adults aged 45 or older reporting SMCs, the three-fourths who had a recent check-up were more likely than those who did not have a recent check-up to discuss their SMCs with a health care professional, but still nearly $75 \%$ had not discussed their memory issues with a health care professional. Adults reporting functional difficulties due to their SMCs were significantly more likely than those without functional difficulties to have talked with a health care professional about their memory problems. Among those with SMCs and functional difficulties, those who had a recent check-up were more likely than those not having one to have talked with a health care professional $(37.4 \%$ [95\% CI, 33.2\%-41.7\%] vs $25.2 \%$ [95\% CI, $19.8 \%-31.5 \%])$. Sex, race/ethnicity, income, insurance status, and reporting a cost barrier to health care were not significantly associated with talking with a health care professional so were excluded from Table 1 and the logistic regression model.

The largest adjusted ORs for talking with a health care professional were for respondents who reported that SMCs always (vs never) caused them to give up household chores (OR, 3.02) or always (vs never) interfered with work (OR, 2.98) and for respondents who were college graduates (OR, 2.42) (Table 2). Compared with residents in California, residents in 7 states were more likely to talk to a health care professional. Others more likely to talk to a health care professional included respondents who had a recent check-up (compared with no recent check-up), had one or more personal doctors (compared with none), had a diagnosis of depression (compared with no such diagnosis), or had a disability (compared with no disability). The likelihood of talking with a health care professional decreased as age increased.

Among respondents reporting SMCs who talked with a health care professional, $41.8 \%$ (95\% CI, 37.2\%-46.5\%) received treatment, representing $9.5 \%$ of all adults aged 45 or older reporting SMCs. Treatment was more likely among respondents who had a diagnosis of dementia (74.3\% [95\% CI, 61.1\%-84.1\%]) than among those with SMCs who did not have a diagnosis of dementia $(7.4 \%[95 \%$ CI, 6.2\%-8.8\%]). However, because so few reported a dementia diagnosis, among study respondents with SMCs who had been treated $(\mathrm{n}=900)$, only $22.6 \%(95 \% \mathrm{CI}, 17.2 \%-29.0 \%)$ reported a diagnosis of dementia.

Among respondents aged 65 or older reporting SMCs, 98.0\% (95\% CI, 97.1\%-98.6\%) had health insurance and 84.2\% (95\% CI, 82.0\%-86.3\%) reported a recent check-up. Among respondents aged 65 or older reporting SMCs, 17.9\% (95\% CI, $15.8 \%-20.3 \%$ ) of those who had a recent check-up versus $11.9 \%$ (95\% CI, 8.2\%-17.0\%) of those not reporting a recent check-up reported talking to a health care professional about their SMCs. Adults aged 65 or older reporting SMCs represent $23.3 \%$ (95\% CI, $21.9 \%-24.7 \%$ ) of respondents of all ages with SMCs.

\section{Discussion}

These results agree with the results of previous studies (15-17) showing that few adults reporting memory problems are discussing them with a health care professional. The current results add to the body of information about such discussions in several ways. First, these results indicate that memory issues are often serious enough to affect daily activities such as household chores, work, or volunteering; however, even among those aged 45 or older most affected by SMCs, only about half reported such discussions. That the likelihood of such discussions decreased with increasing age indicates that even when adjusting for functional difficulties, older adults reporting SMCs are still less likely than adults aged 45 to 54 years to talk with a health care professional about them. This finding might have resulted from older adults feeling that their memory problems are a normal part of aging and nothing can be done about them, but the finding could have resulted from other causes. This finding also suggests that promoting assessments and discussions among adults younger than 65 might be beneficial. The increased likelihood of discussions among adults with disability and depression may indicate that adults reporting these conditions are more comfortable discussing issues with a health care professional or that these conditions create additional problems when combined with memory issues.

The opinions expressed by authors contributing to this journal do not necessarily reflect the opinions of the U.S. Department of Health and Human Services, the Public Health Service, the Centers for Disease Control and Prevention, or the authors' affiliated institutions. 
Having a recent check-up increased the likelihood of discussing memory problems with a health care professional, but only modestly (OR, 1.6). Even among those who had a recent check-up and reported that memory problems were affecting daily activities, only $37.4 \%$ had talked with a health care professional about their memory problems. Of course, any reported discussions could have taken place at some other time and with a different health care provider, but at least a routine check-up should have provided an opportunity for such a discussion. Although it is impossible to know what percentage of these adults reporting memory problems may progress to dementia or Alzheimer's disease, a check-up could represent a missed opportunity for an assessment and discussion of available care, community services, and treatment options at their current stage of memory problems. Discussions could include a check for risk of falls, adherence with prescribed medications, review of exercise, smoking, dietary habits, level of social support, and consideration of future health care plans. Cognitive assessment tools have been developed (6) that could help in stimulating such discussions, and efforts are being made to raise awareness of the need for these activities (18). Because of the Affordable Care Act, those efforts currently focus on the Medicare population, estimated to include $93 \%$ of noninstitutionalized adults aged 65 or older (19). Based on these results for adults aged 65 or older with $\mathrm{SMCs}$, there is room for improvement in discussing memory issues with a health care professional, although no information exists on adults who did not report SMCs. And, as mentioned above, results for adults younger than 65 suggest they might also benefit.

Also new in this study is that $41.8 \%$ of those who talked with a health care professional about their memory problems reported getting treatment. This percentage probably underestimates the percentage of those being treated because only those who said they had such discussions were asked that question, and some may be unaware that treatments they were receiving for other purposes also address memory problems. The data also provide no indication of when treatment occurred in relation to the discussion, what the treatment was, or if it was effective. However, the data suggest that at least in some cases the discussions might lead to treatment, especially because the treatments mentioned in the question were therapy or medications. The finding that those diagnosed with dementia were more likely than those not diagnosed to have been treated is not surprising given that the drugs currently available (20) treat Alzheimer's and dementia rather than mild cognitive impairment. These drugs can temporarily help alleviate memory problems in some people who take them but cannot stop disease progression. New drugs in development may stop or slow the progression of the disease so that diagnosis at an earlier stage may be even more critical.
This study has several limitations. Results are subject to the usual limitations of telephone surveys, including possible bias due to nonresponse and errors caused by self-reporting and recall. Testing of other questions on the BRFSS suggests that the validity of measures in medical records (eg, a dementia diagnosis, recent check-up) is high (21), but the validity of the SMC measure is not known, nor has testing been done among respondents with cognitive impairment. People with dementia may be undiagnosed or unaware of their diagnosis, which might help explain respondents reporting treatment but not a diagnosis of dementia.

These results do not represent all noninstitutionalized adults because the BRFSS random selection process excludes a household if the selected respondent is physically or mentally unable to respond to the survey. A study using data from the cognitive impairment module in Wyoming (8) found that older nonrespondent adults in the household with SMCs for whom the respondent provided proxy responses were more likely to have functional difficulties (57\% of proxied respondents vs $37 \%$ of respondents) and to have talked with a health care professional about their memory issues ( $60 \%$ of proxied respondents vs $23 \%$ of respondents) (8). Using cognitive impairment module data from 13 states (9), similar percentages were found for proxied responses only. Limiting studies to BRFSS respondents may be underestimating the extent of the impact of memory problems in the community. Another study limitation is the lack of information on respondents' perceptions, beliefs, or family history of Alzheimer's or dementia, factors that may affect discussions with health care providers $(15,16)$. The generalizability of the results is unknown because of the state-by-state variation in these results and those reported elsewhere (7).

This study has several strengths. The BRFSS provides a large and representative sample; this study included more than 10,000 adults in 21 states reporting memory problems, and more than 2,200 reported talking with a health care professional about these problems. The study included a large number of variables, including information on demographics, self-reported behaviors, chronic conditions, access to health care, and health status.

These findings suggest that routine check-ups are a missed opportunity for assessing and discussing memory problems for the majority of adults aged 45 or older with SMCs. These results, based only on adults reporting SMCs, highlight the need for the cognitive assessment required in the Affordable Care Act for Medicare recipients and also suggest the need and potential benefits of cognitive assessment among adults younger than 65. Although memory problems could be discussed during any routine checkup, these results show that few adults reporting SMCs, even those with memory problems causing functional difficulties, are avail-

\footnotetext{
The opinions expressed by authors contributing to this journal do not necessarily reflect the opinions of the U.S. Department of Health and Human Services, the Public Health Service, the Centers for Disease Control and Prevention, or the authors' affiliated institutions.
} 
ing themselves of that opportunity. Public health officials and organizations can become involved by raising general awareness of the advantages of early detection of cognitive impairment and dementia and discussions with a health care professional. An example of such a message to health care providers is a letter from the New York State Department of Health that includes information from the Alzheimer's Association on conducting assessments during the Medicare annual wellness visit (22). These actions could potentially result in greater numbers of older adults being diagnosed and treated for memory problems and made aware of available services.

\section{Acknowledgments}

The author thanks the BRFSS coordinators and the survey respondents for their roles in providing the data. This work was completed without outside funding.

\section{Author Information}

Mary Adams, MS, MPH, On Target Health Data LLC, 247 N Stone St, West Suffield, CT 06093. Telephone: 860-370-9035. Email: madams.ontargethealthdata@gmail.com.

\section{References}

1. Cognitive impairment in older adults: screening. Rockville (MD): US Preventive Services Task Force; 2014. http:// www.uspreventiveservicestaskforce.org/Page/Document/ UpdateSummaryFinal/cognitive-impairment-in-older-adultsscreening?ds $=1 \& \mathrm{~s}=$ dementia $\% 20$ screening. Accessed October $5,2015$.

2. Boise L, Eckstrom E, Fagnan L, King A, Goubaud M, Buckley DI, et al. The rural older adult memory (ROAM) study: a practice-based intervention to improve dementia screening and diagnosis. J Am Board Fam Med 2010;23(4):486-98.

3. Freter S, Bergman H, Gold S, Chertkow H, Clarfield AM. Prevalence of potentially reversible dementias and actual reversibility in a memory clinic cohort. CMAJ 1998; 159(6):657-62.

4. Knopman DS, DeKosky ST, Cummings JL, Chui H, CoreyBloom J, Relkin N, et al. Practice parameter: diagnosis of dementia (an evidence-based review). Report of the Quality Standards Subcommittee of the American Academy of Neurology. Neurology 2001;56(9):1143-53.
5. Cordell CB, Borson S, Boustani M, Chodosh J, Reuben D, Verghese J, et al;:Medicare Detection of Cognitive Impairment Workgroup. Alzheimer's Association recommendations for operationalizing the detection of cognitive impairment during the Medicare Annual Wellness Visit in a primary care setting. Alzheimers Dement 2013;9(2):141-50.

6. Cognitive assessment. Chicago (IL): Alzheimer's Association; 2015. http://www.alz.org/health-care-professionals/cognitivetests-patient-assessment.asp\#cognitive_screening. Accessed November 8, 2015.

7. Centers for Disease Control and Prevention (CDC). Selfreported increased confusion or memory loss and associated functional difficulties among adults aged $\geq 60$ years -21 States, 2011. MMWR Morb Mortal Wkly Rep 2013; 62(18):347-50.

8. Cognitive decline among Wyoming adults: results from the 2012 BRFSS. Cheyenne (WY): State of Wyoming Department of Health; 2014.

9. Edwards VJ, Anderson LA, Deokar AJ. Proxy reports about household members with increased confusion or memory loss, 2011 Behavioral Risk Factor Surveillance System. Prev Chronic Dis 2015;12:E47.

10. Anderson LA, Deokar A, Edwards VJ, Bouldin ED, Greenlund KJ. Demographic and health status differences among people aged 45 or older with and without functional difficulties related to increased confusion or memory loss, 2011 Behavioral Risk Factor Surveillance System. Prev Chronic Dis 2015;12:E30.

11. Behavioral Risk Factor Surveillance System: 2011 landline questionnaire data sets. Atlanta (GA): Centers for Disease Control and Prevention; 2012. http://www.cdc.gov/brfss/ annual_data/2011/2011_landline.html. Accessed November 14,2015 .

12. Behavioral Risk Factor Surveillance System. Atlanta (GA). Centers for Disease Control and Prevention (CDC). http:// www.cdc.gov/brfss/about/index.htm. Accessed November 5, 2015.

13. Preparing 2011 BRFSS module data for analysis. Behavioral Risk Factor Surveillance System. Atlanta (GA). Centers for Disease Control and Prevention; 2013. http://www.cdc.gov/ brfss/annual_data/2011/pdf/brfss2011_analysis.pdf. Accessed November 5, 2015.

14. Data quality reports. Behavioral Risk Factor Surveillance System. Atlanta (GA). Centers for Disease Control and Prevention; 2012. http://www.cdc.gov/brfss/annual_data/2011/ pdf/2011_summary_data_quality_report.pdf. Accessed October 6, 2015 .

The opinions expressed by authors contributing to this journal do not necessarily reflect the opinions of the U.S. Department of Health and Human Services, the Public Health Service, the Centers for Disease Control and Prevention, or the authors' affiliated institutions. 
15. Begum A, Whitley R, Banerjee S, Matthews D, Stewart R, Morgan C. Help-seeking response to subjective memory complaints in older adults: toward a conceptual model. Gerontologist 2013;53(3):462-73.

16. Hurt CS, Burns A, Brown RG, Barrowclough C. Why don't older adults with subjective memory complaints seek help? Int J Geriatr Psychiatry 2012;27(4):394-400.

17. Stewart R. Mild cognitive impairment - the continuing challenge of its "real-world" detection and diagnosis. Arch Med Res 2012;43(8):609-14.

18. Hoffman D. Alzheimer's disease legislation and policy - now and in the future. Health Aff (Millwood) 2014;33(4):561-5.

19. A profile of older Americans 2012. Washington (DC): US Department of Health and Human Services, Administration on Aging, Administration for Community Living; 2012. http:// www.aoa.gov/Aging_Statistics/Profile/2012/docs/ 2012profile.pdf. Accessed November 8, 2015.

20. Current Alzheimer's treatment. Chicago (IL): Alzheimer's Association Research Center; 2015. http://www.alz.org/ research/science/alzheimers_disease_treatments.asp\#approved. Accessed October 6, 2015.

21. Pierannunzi C, Hu SS, Balluz L. A systematic review of publications assessing reliability and validity of the Behavioral Risk Factor Surveillance System (BRFSS), 2004-2011. BMC Med Res Methodol 2013;13:49.

22. Letter from the New York State Commissioner of Health, dated November 6, 2013. Albany (NY): New York State Department of Health; 2013. http://www.health.ny.gov/ diseases/conditions/dementia/alzheimer/docs/ dcl_early_detection.pdf. Accessed November 5, 2015.

The opinions expressed by authors contributing to this journal do not necessarily reflect the opinions of the U.S. Department of Health and Human Services, the Public Health Service, the Centers for Disease Control and Prevention, or the authors' affiliated institutions. 


\section{Tables}

Table 1. Self-Reported Discussions With a Health Care Professional About Memory Problems, Adults Aged $\geq 45$ Years Reporting Subjective Memory Complaints, by Selected Characteristicsa, BRFSS in 21 states, 2011

\begin{tabular}{|c|c|c|}
\hline Characteristic & No. of Respondents & Respondents Who Reported Discussion, \% (95\% Cl) \\
\hline All adults aged $\geq 45$ with SMCs & 10,276 & $22.9(21.1-24.9)$ \\
\hline \multicolumn{3}{|l|}{ Age, $y$} \\
\hline $45-54$ & 2,175 & $27.1(23.3-31.2)$ \\
\hline $55-64$ & 2,948 & $24.8(21.6-28.3)$ \\
\hline $65-74$ & 2,439 & $18.0(15.2-21.2)$ \\
\hline $75-84$ & 2,008 & $16.8(13.7-20.4)$ \\
\hline$\geq 85$ & 706 & $14.4(10.3-19.7)$ \\
\hline$P$ value & & $<.001$ \\
\hline \multicolumn{3}{|l|}{ Education } \\
\hline$<$ High school & 1,523 & $19.2(15.6-23.5)$ \\
\hline High school graduate & 3,414 & $21.9(18.6-25.5)$ \\
\hline Some college & 2,790 & $26.2(22.7-30.1)$ \\
\hline College graduate & 2,529 & $24.4(21.2-27.8)$ \\
\hline$P$ value & & .04 \\
\hline \multicolumn{3}{|l|}{ Disability $^{b}$} \\
\hline Any disability & 6,713 & $29.2(26.8-31.8)$ \\
\hline No disability & 3,513 & $11.4(9.3-13.8)$ \\
\hline$P$ value & & $<.001$ \\
\hline \multicolumn{3}{|l|}{ Body mass index, $\mathrm{kg} / \mathrm{m}^{2}$} \\
\hline$<18.5$ & 202 & $24.6(13.5-40.4)$ \\
\hline $18.5-24.5$ & 2,932 & $20.2(17.3-23.5)$ \\
\hline $25.0-29.9$ & 3,401 & $20.4(17.5-23.7)$ \\
\hline $30.0-34.9$ & 1,950 & $23.5(19.6-27.8)$ \\
\hline$\geq 35.0$ & 1,469 & $31.5(26.0-37.5)$ \\
\hline$P$ value & & .002 \\
\hline \multicolumn{3}{|l|}{ Any of 6 chronic diseases ${ }^{c}$} \\
\hline Yes & 8,365 & $24.5(22.4-26.7)$ \\
\hline
\end{tabular}

Abbreviations: BRFSS, Behavioral Risk Factor Surveillance System; Cl, confidence interval; SMC, subjective memory complaint.

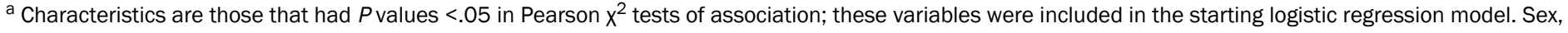

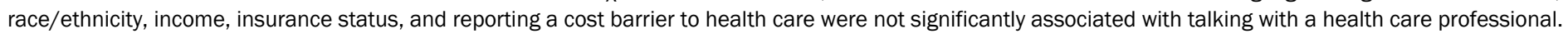

${ }^{\mathrm{b}}$ Defined as limited in any way in any activities or use special equipment.

${ }^{c}$ Chronic diseases are arthritis, asthma, cardiovascular disease, cancer other than skin, chronic obstructive pulmonary disease, and diabetes.

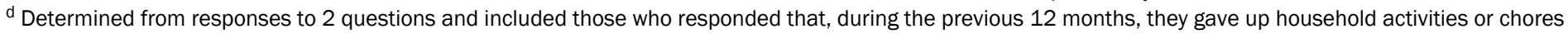

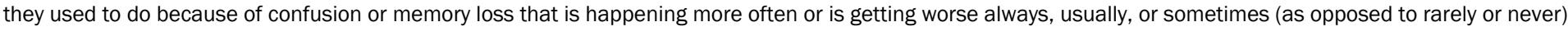

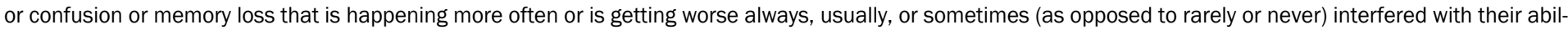
ity to work, volunteer, or engage in social activities, or both.

(continued on next page)

The opinions expressed by authors contributing to this journal do not necessarily reflect the opinions of the U.S. Department of Health and Human Services, the Public Health Service, the Centers for Disease Control and Prevention, or the authors' affiliated institutions. 
(continued)

Table 1. Self-Reported Discussions With a Health Care Professional About Memory Problems, Adults Aged $\geq 45$ Years Reporting Subjective Memory Complaints, by Selected Characteristics ${ }^{a}$, BRFSS in 21 states, 2011

\begin{tabular}{|c|c|c|}
\hline Characteristic & No. of Respondents & Respondents Who Reported Discussion, \% (95\% Cl) \\
\hline No & 1,809 & $17.0(13.3-21.5)$ \\
\hline$P$ value & & .004 \\
\hline \multicolumn{3}{|l|}{ Current smoking } \\
\hline Yes & 2,054 & $27.1(23.1-31.5)$ \\
\hline No & 8,174 & $21.7(19.7-23.8)$ \\
\hline$P$ value & & .02 \\
\hline \multicolumn{3}{|c|}{ Had a routine check-up within the previous year } \\
\hline Yes & 7,909 & $25.2(23.0-27.5)$ \\
\hline No & 2,191 & $16.2(13.3-19.6)$ \\
\hline$P$ value & & $<.001$ \\
\hline \multicolumn{3}{|l|}{ Has $\geq 1$ personal doctors } \\
\hline Yes & 9,493 & $24.3(22.4-26.3)$ \\
\hline No & 753 & $11.3(7.7-16.4)$ \\
\hline$P$ value & & $<.001$ \\
\hline \multicolumn{3}{|l|}{ Health status } \\
\hline Fair or poor & 4,928 & $28.2(25.4-31.2)$ \\
\hline Excellent, very good, or good & 5,309 & $17.6(15.4-20.2)$ \\
\hline$P$ value & & $<.001$ \\
\hline \multicolumn{3}{|l|}{ Ever diagnosed with depression } \\
\hline Yes & 4,254 & $33.2(29.9-36.7)$ \\
\hline No & 5,944 & $14.6(12.8-16.6)$ \\
\hline$P$ value & & $<.001$ \\
\hline \multicolumn{3}{|l|}{ Need help because of SMCs } \\
\hline Yes & 5,324 & $29.0(26.3-31.8)$ \\
\hline No & 4,640 & $15.4(13.1-17.9)$ \\
\hline$P$ value & & $<.001$ \\
\hline \multicolumn{3}{|c|}{ Gave up household activities or chores } \\
\hline Never & 5,632 & $14.5(12.7-16.5)$ \\
\hline
\end{tabular}

Abbreviations: BRFSS, Behavioral Risk Factor Surveillance System; Cl, confidence interval; SMC, subjective memory complaint.

${ }^{a}$ Characteristics are those that had $P$ values $<.05$ in Pearson $x^{2}$ tests of association; these variables were included in the starting logistic regression model. Sex, race/ethnicity, income, insurance status, and reporting a cost barrier to health care were not significantly associated with talking with a health care professional.

${ }^{\mathrm{b}}$ Defined as limited in any way in any activities or use special equipment.

${ }^{\mathrm{C}}$ Chronic diseases are arthritis, asthma, cardiovascular disease, cancer other than skin, chronic obstructive pulmonary disease, and diabetes.

${ }^{\mathrm{d}}$ Determined from responses to 2 questions and included those who responded that, during the previous 12 months, they gave up household activities or chores they used to do because of confusion or memory loss that is happening more often or is getting worse always, usually, or sometimes (as opposed to rarely or never) or confusion or memory loss that is happening more often or is getting worse always, usually, or sometimes (as opposed to rarely or never) interfered with their ability to work, volunteer, or engage in social activities, or both.

The opinions expressed by authors contributing to this journal do not necessarily reflect the opinions of the U.S. Department of Health and Human Services, the Public Health Service, the Centers for Disease Control and Prevention, or the authors' affiliated institutions. 
(continued)

Table 1. Self-Reported Discussions With a Health Care Professional About Memory Problems, Adults Aged $\geq 45$ Years Reporting Subjective Memory Complaints, by Selected Characteristics ${ }^{a}$, BRFSS in 21 states, 2011

\begin{tabular}{|c|c|c|}
\hline Characteristic & No. of Respondents & Respondents Who Reported Discussion, \% (95\% Cl) \\
\hline Rarely & 1,608 & $24.3(20.1-29.0)$ \\
\hline Sometimes & 2,104 & $32.1(27.2-37.3)$ \\
\hline Usually & 428 & $41.9(31.1-53.4)$ \\
\hline Always & 359 & $54.1(43.8-64.1)$ \\
\hline$P$ value & & $<.001$ \\
\hline \multicolumn{3}{|c|}{ SMCs interfere with working, volunteering, or engaging in social activities } \\
\hline Never & 5,183 & $12.5(10.7-14.6)$ \\
\hline Rarely & 1,859 & $21.4(17.8-25.6)$ \\
\hline Sometimes & 1,886 & $33.8(29.1-38.9)$ \\
\hline Usually & 499 & $38.9(29.7-48.9)$ \\
\hline Always & 728 & $51.3(43.1-59.4)$ \\
\hline$P$ value & & $<.001$ \\
\hline \multicolumn{3}{|c|}{ Functional difficulties $^{d}$} \\
\hline Yes & 3,995 & $34.4(30.9-38.0)$ \\
\hline No & 6,205 & $14.5(12.7-16.4)$ \\
\hline$P$ value & & $<.001$ \\
\hline \multicolumn{3}{|l|}{ State of residence } \\
\hline Arkansas & 531 & $22.2(17.7-27.5)$ \\
\hline California & 498 & $14.8(11.6-18.7)$ \\
\hline Florida & 970 & $25.2(20.1-31.1)$ \\
\hline Hawaii & 483 & $24.4(18.0-32.3)$ \\
\hline Illinois & 347 & $24.7(18.2-32.6)$ \\
\hline lowa & 356 & $22.4(17.3-28.5)$ \\
\hline Louisiana & 499 & $32.4(24.9-41.0)$ \\
\hline Maryland & 281 & $18.8(13.7-25.2)$ \\
\hline Michigan & 310 & $24.4(15.9-35.5)$ \\
\hline Nebraska & 858 & $18.2(14.8-22.3)$ \\
\hline New Hampshire & 277 & $28.7(21.7-36.9)$ \\
\hline
\end{tabular}

Abbreviations: BRFSS, Behavioral Risk Factor Surveillance System; Cl, confidence interval; SMC, subjective memory complaint.

${ }^{a}$ Characteristics are those that had $P$ values $<.05$ in Pearson $x^{2}$ tests of association; these variables were included in the starting logistic regression model. Sex, race/ethnicity, income, insurance status, and reporting a cost barrier to health care were not significantly associated with talking with a health care professional.

${ }^{\mathrm{b}}$ Defined as limited in any way in any activities or use special equipment.

${ }^{\mathrm{C}}$ Chronic diseases are arthritis, asthma, cardiovascular disease, cancer other than skin, chronic obstructive pulmonary disease, and diabetes.

${ }^{\mathrm{d}}$ Determined from responses to 2 questions and included those who responded that, during the previous 12 months, they gave up household activities or chores they used to do because of confusion or memory loss that is happening more often or is getting worse always, usually, or sometimes (as opposed to rarely or never) or confusion or memory loss that is happening more often or is getting worse always, usually, or sometimes (as opposed to rarely or never) interfered with their ability to work, volunteer, or engage in social activities, or both.

(continued on next page)

The opinions expressed by authors contributing to this journal do not necessarily reflect the opinions of the U.S. Department of Health and Human Services, the Public Health Service, the Centers for Disease Control and Prevention, or the authors' affiliated institutions. 
(continued)

Table 1. Self-Reported Discussions With a Health Care Professional About Memory Problems, Adults Aged $\geq 45$ Years Reporting Subjective Memory Complaints, by Selected Characteristicsa, BRFSS in 21 states, 2011

\begin{tabular}{|l|r|r|}
\hline Characteristic & No. of Respondents & Respondents Who Reported Discussion, \% (95\% Cl) \\
\hline New York & 210 & $25.3(18.4-33.8)$ \\
\hline North Carolina & 661 & $25.2(20.7-30.2)$ \\
\hline Oklahoma & 335 & $25.3(20.1-31.2)$ \\
\hline South Carolina & 941 & $20.9(16.4-26.2)$ \\
\hline Tennessee & 248 & $33.4(26.1-41.6)$ \\
\hline Texas & 581 & $31.9(25.4-39.1)$ \\
\hline Utah & 242 & $20.9(14.9-28.6)$ \\
\hline Washington & 1,036 & $19.6(16.6-23.1)$ \\
\hline West Virginia & 278 & $32.0(25.8-38.8)$ \\
\hline Wisconsin & 334 & $18.4(12.9-25.7)$ \\
\hline Pvalue & $<.001$ \\
\hline
\end{tabular}

Abbreviations: BRFSS, Behavioral Risk Factor Surveillance System; Cl, confidence interval; SMC, subjective memory complaint.

${ }^{a}$ Characteristics are those that had $P$ values $<.05$ in Pearson $x^{2}$ tests of association; these variables were included in the starting logistic regression model. Sex, race/ethnicity, income, insurance status, and reporting a cost barrier to health care were not significantly associated with talking with a health care professional.

${ }^{\mathrm{b}}$ Defined as limited in any way in any activities or use special equipment.

${ }^{\mathrm{c}}$ Chronic diseases are arthritis, asthma, cardiovascular disease, cancer other than skin, chronic obstructive pulmonary disease, and diabetes.

${ }^{\mathrm{d}}$ Determined from responses to 2 questions and included those who responded that, during the previous 12 months, they gave up household activities or chores they used to do because of confusion or memory loss that is happening more often or is getting worse always, usually, or sometimes (as opposed to rarely or never) or confusion or memory loss that is happening more often or is getting worse always, usually, or sometimes (as opposed to rarely or never) interfered with their ability to work, volunteer, or engage in social activities, or both.

The opinions expressed by authors contributing to this journal do not necessarily reflect the opinions of the U.S. Department of Health and Human Services, the Public Health Service, the Centers for Disease Control and Prevention, or the authors' affiliated institutions. 
Table 2. Results of Logistic Regression Modela for the Outcome Measure of Talking With a Health Care Professional About Memory Problems, Respondents Aged $\geq 45$ Years Reporting Subjective Memory Complaints $(\mathrm{N}=$ 9,724 ), BRFSS, 21 states, 2011

\begin{tabular}{|c|c|}
\hline Group & Adjusted OR (95\% Cl) \\
\hline \multicolumn{2}{|l|}{ Age group, $y$} \\
\hline $45-54$ & 1.0 [Reference] \\
\hline $55-64$ & $0.80(0.60-1.05)$ \\
\hline $65-74$ & $0.68(0.49-0.93)$ \\
\hline $75-84$ & $0.66(0.46-0.95)$ \\
\hline$\geq 85$ & $0.58(0.36-0.95)$ \\
\hline \multicolumn{2}{|l|}{ Education } \\
\hline$<$ High school & 1.0 [Reference] \\
\hline High school graduate & $1.39(0.98-1.99)$ \\
\hline Some college & $2.00(1.39-2.87)$ \\
\hline College graduate & $2.42(1.68-3.48)$ \\
\hline \multicolumn{2}{|c|}{ Had a routine check-up within the previous year } \\
\hline No & 1.0 [Reference] \\
\hline Yes & $1.63(1.20-2.21)$ \\
\hline \multicolumn{2}{|c|}{ Has $\geq 1$ personal doctors } \\
\hline No & 1.0 [Reference] \\
\hline Yes & $2.24(1.41-3.57)$ \\
\hline \multicolumn{2}{|c|}{ Ever been diagnosed with depression } \\
\hline No & 1.0 [Reference] \\
\hline Yes & $1.66(1.30-2.13)$ \\
\hline \multicolumn{2}{|l|}{ Disabilityc } \\
\hline No & 1.0 [Reference] \\
\hline Yes & $1.81(1.38-2.37)$ \\
\hline \multicolumn{2}{|c|}{ Gave up household activities or chores } \\
\hline Never & 1.0 [Reference] \\
\hline Rarely & $1.38(0.98-1.93)$ \\
\hline Sometimes & $1.52(1.13-2.06)$ \\
\hline Usually & $1.62(0.93-2.82)$ \\
\hline Always & $3.02(1.81-5.05)$ \\
\hline SMCs interfere with $\mathrm{w}$ & \\
\hline
\end{tabular}

Abbreviations: BRFSS, Behavior Risk Factor Surveillance System; Cl, confidence interval; OR, odds ratio; SMC, subjective memory complaint.

${ }^{a}$ The final logistic regression model excluded smoking, chronic diseases, body mass index, functional difficulties, and needing help due to SMCs because these variables were not found to be significant in the starting logistic model. The starting logistic regression model included all of the variables found in Table 1: age; education; disability; body mass index; chronic diseases; current smoking; check-up in previous year; one or more personal doctors; health status; ever diagnosed with depression; need help due to SMCs; gave up household chores or activities; SMCs interfere with work, volunteering, or engagement in social activities; functional difficulties; state of residence.

${ }^{\mathrm{b}}$ Sample size reflects the removal of 552 respondents for whom values for variables in the model were missing.

${ }^{\mathrm{C}}$ Defined as limited in any way in any activities or use special equipment.

(continued on next page)

The opinions expressed by authors contributing to this journal do not necessarily reflect the opinions of the U.S. Department of Health and Human Services, the Public Health Service, the Centers for Disease Control and Prevention, or the authors' affiliated institutions. 
(continued)

Table 2. Results of Logistic Regression Modela for the Outcome Measure of Talking With a Health Care Professional About Memory Problems, Respondents Aged $\geq 45$ Years Reporting Subjective Memory Complaints $\left(\mathrm{N}=9,724^{\mathrm{b}}\right)$, BRFSS, 21 states, 2011

\begin{tabular}{|c|c|}
\hline Group & Adjusted OR (95\% Cl) \\
\hline Never & 1.0 [Reference] \\
\hline Rarely & $1.41(1.02-1.95)$ \\
\hline Sometimes & $2.19(1.60-3.01)$ \\
\hline Usually & $2.21(1.38-3.53)$ \\
\hline Always & $2.98(1.89-4.70)$ \\
\hline \multicolumn{2}{|l|}{ State of residence } \\
\hline California & 1.0 [Reference] \\
\hline Arkansas & $1.29(0.83-2.01)$ \\
\hline Florida & $1.43(0.95-2.15)$ \\
\hline Hawaii & $1.83(1.05-3.19)$ \\
\hline Illinois & $1.61(1.00-2.58)$ \\
\hline lowa & $1.49(0.96-2.30)$ \\
\hline Louisiana & $1.85(1.14-3.00)$ \\
\hline Maryland & $1.17(0.65-2.10)$ \\
\hline Michigan & $1.33(0.74-2.40)$ \\
\hline Nebraska & $1.03(0.68-1.55)$ \\
\hline New Hampshire & $1.75(1.07-2.85)$ \\
\hline New York & $1.51(0.83-2.77)$ \\
\hline North Carolina & $1.35(0.89-2.05)$ \\
\hline Oklahoma & $1.27(0.81-1.98)$ \\
\hline South Carolina & $1.10(0.69-1.73)$ \\
\hline Tennessee & $2.08(1.21-3.59)$ \\
\hline Texas & $2.05(1.34-3.12)$ \\
\hline Utah & $1.18(0.67-2.07)$ \\
\hline Washington & $1.17(0.80-1.71)$ \\
\hline West Virginia & $1.94(1.22-3.08)$ \\
\hline Wisconsin & $1.22(0.68-2.21)$ \\
\hline
\end{tabular}

Abbreviations: BRFSS, Behavior Risk Factor Surveillance System; Cl, confidence interval; OR, odds ratio; SMC, subjective memory complaint.

${ }^{a}$ The final logistic regression model excluded smoking, chronic diseases, body mass index, functional difficulties, and needing help due to SMCs because these variables were not found to be significant in the starting logistic model. The starting logistic regression model included all of the variables found in Table 1: age; education; disability; body mass index; chronic diseases; current smoking; check-up in previous year; one or more personal doctors; health status; ever diagnosed with depression; need help due to SMCs; gave up household chores or activities; SMCs interfere with work, volunteering, or engagement in social activities; functional difficulties; state of residence.

${ }^{\mathrm{b}}$ Sample size reflects the removal of 552 respondents for whom values for variables in the model were missing.

${ }^{\mathrm{c}}$ Defined as limited in any way in any activities or use special equipment.

The opinions expressed by authors contributing to this journal do not necessarily reflect the opinions of the U.S. Department of Health and Human Services, the Public Health Service, the Centers for Disease Control and Prevention, or the authors' affiliated institutions. 